\title{
Prevalence and risk factors for obesity in a Nigerian obstetric population
}

\author{
Ajen Stephen Anzaku ${ }^{1, *}$, Achara Amaechi Peter ${ }^{2}$, Akaba Godwin Otuodichinma ${ }^{3}$, \\ Yakubu Emmanuel Nyam ${ }^{4}$ \\ ${ }^{1}$ Department of Obstetrics and Gynaecology, College of Health Sciences, Bingham University, Jos campus, Jos, Nigeria \\ ${ }^{2}$ Department of Obstetrics and Gynaecology, Federal Medical Centre, Keffi, Nigeria \\ ${ }^{3}$ Department of Obstetrics and Gynaecology, University of Abuja Teaching Hospital, Gwagwalada, Nigeria \\ ${ }^{4}$ Department of Obstetrics and Gynaecology, Jos University Teaching Hospital, Jos, Nigeria
}

\section{Email addresses:}

steveanzaku@gmail.com (Anzaku S. A.), achapet2005@yahoo.com (Achara A. P.), docakabago@yahoo.com (Akaba G. O.), emayaks75@yahoo.com (Yakubu E. N.)

\section{To cite this article:}

Ajen Stephen Anzaku, Achara Amaechi Peter, Akaba Godwin Otuodichinma, Yakubu Emmanuel Nyam. Prevalence and Risk Factors for Obesity in a Nigerian Obstetric Population. American Journal of Health Research. Vol. 2, No. 5, 2014, pp. 229-233.

doi: 10.11648/j.ajhr.20140205.12

\begin{abstract}
Background: An obese pregnant woman is at increased risk of pregnancy complications with resultant adverse pregnancy outcomes. This study was undertaken to ascertain the magnitude of this nutritional disorder and its predictive factors among an obstetric population in Nigeria. Materials and methods: A descriptive study of pregnant women who registered for antenatal care within the first trimester in a private University Teaching Hospital over a 7-month period. They were interviewed to document the requisite data, their weights and heights were also taken. Body mass index obesity and obesity were classified based on the WHO criteria. Data was analyzed using SPSS version 16 for windows (SPSS Inc., Chicago, IL, USA). Results: The mean weight and height of the women were $71.2 \pm 14.9 \mathrm{Kg}$ and $1.59 \pm 0.06$ meters respectively. The prevalence of obesity was 33.1\%. Thirty two women (60.4\%) had mild obesity, 16 (30.2\%) had moderate obesity while $5(9.4 \%)$ had severe or morbid obesity. Also, 32.5\% (52/160) of the study population were overweight while $34.4 \%(55 / 160)$ had normal BMI. Maternal age $>35$ years $(\mathrm{P}=0.04$, OR $3.9,95 \%$ CI $1.01-8.15)$, history of previous delivery $(\mathrm{P}=0.03$, OR $4.8,95 \% \mathrm{CI} 1.08-5.55)$ and self-reported satisfactory income $(\mathrm{P}=0.03, \mathrm{OR} 4.6,95 \% \mathrm{CI} 1.11-$ 8.86) were significant independent predictive factors of obesity among the study population. Conclusion: Obesity is common in this obstetric population and older women, previous delivery and self-reported satisfactory income were its predictive factors. The need for prenatal health awareness about obesity and identification of these women aimed at instituting early antenatal surveillance and identification of complication(s) is advocated.
\end{abstract}

Keywords: Obesity, Body Mass Index, Risk Factors, Obstetric Population, Nigeria

\section{Introduction}

Obesity defined as body mass index (BMI) greater or equal to $30 \mathrm{Kg} / \mathrm{m}^{2}$ is one of the emerging public health concern particularly in developed countries and its prevalence has risen to an epidemic proportion ${ }^{1,2}$. It has been estimated that about $20 \%$ of pregnant women booking for antenatal care in the United Kingdom (UK) are obese ${ }^{3}$. This nutritional disorder is associated deleterious effects on female reproduction, pregnancy outcomes as well as a contributor to maternal mortality ${ }^{4,5}$. Hence, obesity has major impacts on maternity services including significant implications for the delivery of obstetric care in any society.

There are reports of increasing prevalence of obesity among pregnant women in developing countries 6,7 . Increased rates of obesity among pregnant women are a significant public health concern with wide implications for prenatal care and supervision of delivery. This may ultimately increase the cost of obstetric care as a result of negative impacts of obesity in pregnancy including increased risk of miscarriages, gestational hypertension and pre-eclampsia, gestational diabetes, prolonged pregnancy, increased caesarean section rates, postpartum hemorrhage, fetal macrosomia and fetal deaths. In Nigeria, there are 
reports of significant level of obesity in pregnancy in the South-eastern parts of the country with prevalence range of 10.7 to $22.6 \%$ with associated reported adverse maternal and fetal outcomes ${ }^{8,9}$.

The World Health Organization (WHO) describes obesity as "one of the most blatantly visible, yet most neglected, public-health problems that threaten to overwhelm both developed and developing countries"10. Hence, obesity is conferring a high risk status to pregnant women and there may be the need for routine antenatal identification of these so that appropriative proactive are instituted to reduce the poor obstetric outcomes associated with this emerging health risk.

Several risk factors for obesity in pregnancy have been identified in published literatures including urban residence, increasing maternal age, women of high parity, cigarette smoking and lower educational status ${ }^{7,8,11}$. Identification of risk factors for obesity in an antenatal population may prompt the need among health professionals to purposefully screen for the disorder.

To the best of our knowledge no study has been carried out on the prevalence and risk factors for obesity among the obstetric population in Jos, North-central Nigeria. This study was therefore undertaken to ascertain the magnitude and independent risk factors of obesity at booking in a Nigerian obstetric population in Jos.

\section{Materials and Methods}

This was a cross-sectional study of consecutive pregnant women presenting for antenatal care booking within the first trimester at Bingham University Teaching Hospital, Jos from January to July 2013. Bingham University Teaching Hospital, Jos, formerly ECWA Evangel Hospital, is a 250-bed private tertiary Hospital involved in training of medical students of the College of Health Sciences, Bingham University, Karu. It is also a center for postgraduate training in Family Medicine and serves as a referral center for hospitals throughout Plateau State and neighboring states. The hospital offers specialist services in all clinical areas including Obstetrics and Gynecology, Pediatrics, Surgery and Medicine. Dating of pregnancy was done using self-reported last menstrual period and confirmed by ultrasound. Women with multiple gestations, booking after the first trimester and those with any pre-pregnancy chronic medical conditions (e.g. hypertension, diabetes, and sickle cell disease) were excluded from the study.

Verbal consent was obtained from the women and they were interviewed using a pre-designed questionnaire to obtain their socio-demographic and obstetric parameters. The weight and height of each participant were taken using standard technique and recorded appropriately. An instrument with weighing scale/Stadiometer components $\left(\right.$ Detecto $^{\mathrm{R}}$ ) was used for this purpose. The Weighing scale and Stadiometer components of the instrument have accuracy of within $0.1 \mathrm{Kg}$ and $0.1 \mathrm{~cm}$ respectively. The $\mathrm{BMI}$ were classified according to $\mathrm{WHO}^{12}$ as; Underweight $\left(<18.5 \mathrm{Kg} / \mathrm{m}^{2}\right)$, Normal $\left(18.5-24.9 \mathrm{Kg} / \mathrm{m}^{2}\right)$, Overweight $\left(25.0-29.9 \mathrm{~kg} / \mathrm{m}^{2}\right)$ and Obese $\left(\geq 30 \mathrm{Kg} / \mathrm{m}^{2}\right)$.

Sample size of 147 was calculated using the formula $\mathrm{n}=$ $\mathrm{Z}^{2} \mathrm{Pq} / \mathrm{d}^{2}$ and a prevalence rate of $10.7 \%$ reported by Chigbu $\mathrm{CO}$ et al ${ }^{8}$ from South-east Nigeria was used. Also, the sample size was adjusted to compensate for $5 \%$ possible attrition rate and thus, the minimum sample size was 154 . Statistical analysis was done using SPSS 16 (SPSS Inc., Chicago, IL, USA) and results expressed as percentages and Mean \pm Standard deviation. Chi square test was used to identify association between variables and obesity in pregnancy. Significant predictive factors on univariate analysis were subjected to multivariate logistic regression analysis to ascertain independent risk factors of obesity in pregnancy. $\mathrm{P}$ value $<0.05$ at $95 \%$ confidence interval was considered as statistically significant. Ethical clearance was obtained from the Human Research and Ethics Committee (HREC) of Bingham University Teaching Hospital, Jos.

\section{Results}

A total of 160 eligible pregnant women who consented for the study were recruited and participated in the study. The women booked for antenatal care between $7-13$ weeks of gestation with average gestational age of $11.7 \pm$ 1.3 weeks. The parity of the women ranged between 0 and 7. Their mean age was $30.3 \pm 4.6$ years with a range of $19-$ 43 years. Most of them $(61.9 \%)$ had tertiary education and amongst those that were employed (self-employed or employed by government or private organizations), $14.4 \%$ $(23 / 160)$ had self-reported satisfactory income. Table 1 shows the socio-demographic features of the study population.

The mean weight of the women was $71.2 \pm 14.9 \mathrm{Kg}$ while the mean height was $1.59 \pm 0.06$ meters respectively. The range of their heights and weight were $40-154 \mathrm{Kg}$ and $1.46-1.74$ respectively. The average BMI was 28.3 $\mathrm{Kg} / \mathrm{m}^{2}$ with a range of $18.6-72.5 \mathrm{Kg} / \mathrm{m}^{2}$. About one-third of the women who participated in the study were obese (33.1\%) and out of these, $32(60.4 \%)$ of them had mild obesity, $16(30.2 \%)$ moderate obesity while $5(9.4 \%)$ had severe or morbid obesity. However, $32.5 \%(52 / 160)$ of the study population were overweight while $34.4 \%(55 / 160)$ had normal BMI. None of the women was underweight. Table 2 depicts the obstetric and anthropometric characteristics of the study population.

Univariate analysis revealed association between obesity in pregnancy and maternal age $>35$ years, history of previous delivery, last childbirth $\geq 5$ years, and selfreported satisfactory income. Table 3 shows the results of univariate analysis. However, on multivariate logistic regression, only maternal age $>35$ years $(\mathrm{P}=0.04$, OR 3.9, $95 \%$ CI $1.01-8.15)$, history of previous delivery $(\mathrm{P}=0.03$, OR 4.8, 95\% CI $1.08-5.55)$ and self-reported satisfactory $(\mathrm{P}=0.03$, OR 4.6, 95\% CI $1.11-8.86)$ were significant independent risk factors of obesity among this study population. 
Table 1. Socio-demographic features of the study population

\begin{tabular}{lll}
\hline Features & Frequency & Percentage \\
\hline Age (Years) & 2 & \\
$\leq 20$ & 21 & 1.2 \\
$21-25$ & 70 & 13.1 \\
$26-30$ & 46 & 43.8 \\
$31-35$ & 18 & 28.8 \\
$36-40$ & 3 & 11.2 \\
$>40$ & 160 & 1.9 \\
Total & & 100.0 \\
Ethnic group & 36 & \\
Igbo & 25 & 22.5 \\
Berom & 16 & 15.6 \\
Yoruba & 12 & 10.0 \\
Irigwe & 10 & 7.5 \\
Rukuba & 61 & 6.3 \\
Others & & 38.1 \\
Total & 160 & 100.0 \\
Educational Level & & \\
Primary & 5 & 3.1 \\
Secondary & 56 & 35.0 \\
Tertiary & 99 & 61.9 \\
Total & 160 & 100.0 \\
Employment Status & & \\
Employed & 34 & 21.2 \\
Self-employed & 75 & 46.9 \\
Unemployed & 51 & 31.9 \\
Total & 160 & 100.0 \\
Level of income & & \\
Satisfactory & 23 & 14.4 \\
Unsatisfactory & 86 & 53.7 \\
Unemployed & 51 & 31.9 \\
Total & 160 & 100.0 \\
\hline
\end{tabular}

Others ${ }^{\ddagger}$ Include - Ngas, Mwaghvul, Tarok, Idoma, Eggon, Chawai, Tiv, Kataf, Mada, Fulani, Mupun, Tangalle, Ron, Anaguta, Kwalla, Afizare, Baju, Igala, Sayawa

Table 2. Obstetrics and anthropometric characteristics of the Woman

\begin{tabular}{lll}
\hline Features & Frequency & Percentage \\
\hline Parity & & \\
0 & 64 & 40.0 \\
$1-4$ & 87 & 54.4 \\
$\geq 5$ & 9 & 5.6 \\
Total & 160 & 100.0 \\
Gestational age at booking & & \\
$7-9$ & 10 & 6.2 \\
$10-12$ & 99 & 61.9 \\
13 & 51 & 31.9 \\
Total & 160 & 100.0 \\
Weight $(\mathrm{Kg})$ & & \\
$\leq 60$ & 38 & 23.8 \\
$61-80$ & 86 & 53.7 \\
$81-100$ & 27 & 16.9 \\
$101-120$ & 4 & 2.5 \\
$>120$ & 5 & 3.1 \\
Total & 160 & 100.0 \\
Height $($ Metres $)$ & & \\
$\leq 1.50$ & 16 & 10.0 \\
$1.51-1.60$ & 83 & 51.9 \\
$1.61-170$ & 58 & 36.2 \\
$>170$ & 3 & 1.9 \\
Total & 160 & 100.0 \\
Body Mass Index $\left(\mathrm{Kg} / \mathrm{m}^{2}\right)$ & & \\
$18.5-24.9$ & 55 & 34.4 \\
$25.0-29.9$ & 52 & 32.5 \\
$\geq 30$ & 53 & 33.1 \\
Total & 160 & 100.0 \\
\hline & &
\end{tabular}

Table 3. Univariate analysis of risk factors for obesity in pregnancy

\begin{tabular}{llll}
\hline Risk Factors & P value & Odd Ratio (OR) & $\mathbf{9 5 \% ~ C I ~}$ \\
\hline Age $>$ 35 & 0.004 & 4.02 & $1.55-10.44$ \\
Ethnic group & 0.44 & 0.73 & $0.32-1.64$ \\
Educational level & 0.78 & 0.91 & $0.46-1.79$ \\
Employment status & 0.26 & 1.56 & $0.72-3.41$ \\
Income level & 0.004 & 3.91 & $1.56-9.77$ \\
Parity $(\geq 1)$ & 0.006 & 2.80 & $1.35-5.83$ \\
Last Childbirth $\geq 5$ & 0.04 & 2.55 & $1.04-6.26$ \\
years
\end{tabular}

\section{Discussion}

Obesity considered as one of the emerging serious global health problems of the $21^{\text {st }}$ centuary by the world Health Organization (WHO) has been demonstrated to be common in this Nigerian obstetric population with a prevalence of $33.1 \%$. This is likely to be the true picture of obesity rate among this group of women as there is a good correlation between pre-pregnancy weights and those at early booking ${ }^{13}$. Hence, the differences in obesity rates at preconceptional period and early in pregnancy as conducted in this study have been found to be statistically insignificant ${ }^{8}$. The prevalence of obesity among early booked pregnant women found in this study is however higher than the reported range of obesity among pregnant women of $1.8-25.3 \%$ quoted by $\mathrm{WHO}^{4}$. Surprisingly, the value from our study is also about three times the reported rates of $7.4-10.7 \%$ from other regions of the country ${ }^{8,14,15}$, but a high rate of $22.6 \%$ has also been reported from Abakaliki, Southeastern Nigeria ${ }^{9}$.

These differing rates in the country may be attributable to the different obstetric populations with different life styles and dietary habits. Also, the varied periods in pregnancy in which these researches were conducted compared to this study probably influenced the rates of obesity reported. The finding of high rate of obesity in this study may be attributable to the advancing modernity of Nigerian women which is influenced by Caucasian life styles and dietary pattern obtainable from an urban setting like Jos. Dietary pattern have been known to influence rate of obesity ${ }^{7,8}$. Also, the high prevalence of obesity in this study may have also been influenced by the high socio economic status of the participants who were majorly well educated and income earners .Their ability to pay for services in a private tertiary hospital supports this view.

Compared to African clinical settings, the reported figure is about four times higher than obesity rate of $17.9 \%$ from Ghana and twice higher than $9.1 \%$ reported from Tanzania ${ }^{6,16}$ even though the researches were also conducted among urban obstetric populations. The level of under-nutrition among the study populations in the studies from Tanzania and Ghana probably contributed to these lower rates as some of the women were either underweight or wasted compared to none in this study. 
However, this reported high rate of obesity is comparable to those from other countries, with figures of $28.6 \%$ and $38.3 \%$ from Saudi Arabia and United States of America ${ }^{7,17}$ but lower than figures of $13.5 \%$ and $10.9 \%$ among pregnant women at booking in Australia and UK respectively ${ }^{11,18}$. This may be attributable to differences in dietary life styles in this urban obstetric population compared to that of Caucasian settings as well as differing study populations.

About $32.5 \%$ of the women were overweight, and this is higher than $14.0 \%$ from Enugu, Nigeria ${ }^{8}$ and $23.6 \%$ from Saudi Arabia ${ }^{7}$ but lower than figure of $50.7 \%$ reported Benin ${ }^{19}$. The use of women scheduled for caesarean section in their third trimester as the study population in the Benin study and the limitation of using body mass index in assessing obesity in this group may be responsible for the very high rate reported.

Previous delivery (parity), maternal age $>35$ years and satisfactory income were independent factors predictive of obesity in this study population. The risk of obesity increases 4.8-fold among women with parity of 1 or more compared to nulliparous women. This is in agreement with findings from other studies ${ }^{7,8,20,21}$. This may be related to the tendency to gain weight with each pregnancy and the fact that parous women tend to retain more of the weight gained during pregnancy $21-23$. There is a direct relationship between older aged women and obesity in this study. This corroborate with findings from other studies $9,11,24$ but contrary to what was reported elsewhere $7,8,20$. This may reflect physiological changes associated with increased adiposity with increasing age and more so older women are more likely to be parous, with weight gain during previous pregnancies cumulatively predisposing them to obesity.

Women with self-reported satisfactory income are about five times more likely to be obese compared to those with unsatisfactory income. A number of studies have shown a positive relationship between satisfactory income and obesity ${ }^{7,11}$ but contrary to reports by other researchers ${ }^{25,26}$. This finding may be a reflection of their sedentary life style and pattern of dietary consumption. Moreover, modern diets of developed countries in which affluent populace in developing countries are imbibing contain more fat and significantly less fibre and this is a significant contributor to the burden of obesity ${ }^{27}$.

The limitations of this study included its private hospitalbased nature and the exclusion of late attendees from the study. The findings therefore may not be a true reflection of the disorder in the general populace. This study however adds to the body of evidences that suggest obesity is becoming common amongst pregnant women in developing countries.

\section{Conclusion}

Obesity in pregnancy is common in this obstetric population especially among women aged $>35$ years, parous women and those with satisfactory income. Prenatal health education about risks of obesity and its screening is therefore recommended so as to institute counseling regarding weight gain, nutrition, and food choices. It may also lead to early detection and treatment of complications associated with this emerging disorder.

\section{Acknowledgments}

We wish express our gratitude to the Nurses and other health workers at the antenatal clinic for their contribution in taking the weights and heights of the women.

\section{References}

[1] Cameron AJ, Welborn TA, Zimmet PZ. Overweight and obesity in Australia: the 1999 - 2000 Australian Diabetes, Obesity and lifestyle study (AustDiab). Med J Aust 2003; 178: $427-432$.

[2] Hall LF, Nanbert G. Obesity and pregnancy. Obstet Gynecol Surv 2005; 60: $253-60$.

[3] Kanagalingam MG, Forouhi NG, Greer IA, Sattar N. Changes in booking body mass index over a decade: retrospective analysis from a Glasgow Maternity Hospital. BJOG 2005; 112: 1431 - 3 .

[4] Guelinckx I, Devlieger R, Beckers K, Vansant G. Maternal obesity: pregnancy complications, gestational weight gain and nutrition. Obes Rev 2008; 9: 140 - 50.

[5] Al-Malki JS, Al-Jaser MH, Warsy AS. Overweight and obesity in Saudi females of childbearing age. Int J Obesity 2008; $27: 134-9$.

[6] Addo VN. Body mass index, weight gain during pregnancy and obstetric outcomes. Ghana Med J 2010; 44: 64 - 9.

[7] El-Gilany A, El-Wehady A. Prevalence of obesity in a Saudi obstetric population. Obes Facts 2009; 2: $217-20$.

[8] Chigbu CO, Aja LO. Obesity in pregnancy in Southeast Nigeria. Ann Med Health Sci Res 2011; 1: 135 - 40.

[9] Ugwuja EI, Akubugwo EI, Obidoa O, Ibiam AU. Maternal BMI during pregnancy: Effect of trace elements status and pregnancy outcomes. Int J Health Res 2010; 3: $71-8$.

[10] Vyas S, Ghani L, Khazaezadeh N, Oteng-Ntim E. Pregnancy and obesity. In: Studd J, Tan SL, Chervenak FA (eds). Progress in Obstetrics and Gynaecology, Vol 18. London, Elsevier Ltd, 2008; $11-28$.

[11] Callaway LK, Prins JB, Chang AM, McIntyre HD. The prevalence and impact of overweight and obesity in an Australian obstetric population. Med J Aust 2006; 184: 56 9.

[12] WHO. Obesity: prevention and managing the global epidemic. Report of a WHO Consultation. WHO Technical Report Series 894. Geneva, World Health Organization, 2000 .

[13] Mamun AA, Lawlor DA, O'callaghan MJ, Williams JM, Najman JM. Family and early life factors associated with changes in overweight status between ages 5 and 14 years: findings from the Mater University study of pregnancy and its outcomes. Int J Obes 2005; 29: 475 - 82. 
[14] Olayemi OO, Umuerri CO, Aimakhu CO. Obstetric performance of Nigerian obese parturients. Trop J Obstet Gynaecol 2002; 19: $17-20$.

[15] Ezeanochie MC, Ande AB, Olagbuji BN. Maternal obesity in early pregnancy and subsequent pregnancy outcome in a Nigerian population. Afr J Reprod Health 2011; 15: 55 - 9.

[16] Villamor E, Msamanga G, Urassa W, Petraro P, Spiegelman $\mathrm{D}$, Hunter DJ et al. Trends in obesity, underweight and wasting among women attending prenatal clinics in urban Tanzania, 1995 - 2004. Am J Clin Nutr 2006; 83: 1387 - 94.

[17] Galtier-Dereure F, Boegner C, Bringer J. Obesity and pregnancy: complications and cost. Am J Clin Nutr 2000; 71: $12825-85$.

[18] Sebire NJ, Jolly M, Harris JP, Wadsworth J, Joffe M, Beard RW, et al. Maternal obesity and pregnancy outcome: a study of 287,213 pregnancies in London. Int J Obes Relat Metab Disord 2001; 25: 1175 - 82 .

[19] Edomwonyi NP, Osaigbovo PE. Incidence of obesity in parturients scheduled for caesarean section, intra-operative complications, management and outcome. East Afr Med J 2006; 83: $112-9$.

[20] Obi SN, Obute EA: Pregnancy outcome in the obese Nigerian. Trop J Obstet Gynaecol 2004; 21: 32 - 5.
[21] Koch E, Bogado M, Araya F, Romero T, Díaz C, Manriquez $\mathrm{L}$, et al. Impact of parity on anthropometric measures of obesity controlling by multiple confounders: a crosssectional study in Chilean women. J Epidemiol Community Health 2008; 62: $461-70$.

[22] Schauberger CW, Rooney BL \& Brimer LM. Factors that influence weight loss in the puerperium. Obstetrics and Gynecology 1992; 79: $424-9$.

[23] Polley BA, Wing RR, Sims CJ. Randomized controlled trial to prevent excessive weight gain in pregnant women. Int J Obes Relat Metab Disord 2002; 26: 1494 - 502.

[24] Bhattacharya S, Campbell DM, Liston WA, Bhuttacharya S. Effect of body mass index on pregnancy outcomes in nulliparous women delivering singleton babies. BMC Public Health 2007; 7: $168-72$.

[25] Sobal J, Stunkard A. Socioeconomic status and obesity: a review of the literature. Psych Bull 1989; 105: 260 - 75.

[26] Lahmann PH, Lissner L, Gullberg B, Berglund G. Sociodemographic factors associated with long-term weight gain, current body fatness and central adiposity in Swedish women. Int J Obes Relat Metab Diord 2000;24: 685 - 94.

[27] Willett WC. Dietary fat plays a major role in obesity. Obesity Rev 2002; 3: $59-68$. 